\title{
Effects of aprepitant /dexamethasone versus mirtazapine/dexamethasone on postoperative nausea and vomiting after laparoscopic sleeve gastrectomy: a randomized controlled trial
}

\author{
Tarek Ashoor ( $\square$ tarekashoor@med.asu.edu.eg) \\ Ain Shams University \\ Dina Y. Kassim \\ Beni-Suef University \\ Ahmed M. Hasseb \\ Ain Shams University \\ Ibrahim M. Esmat
}

Ain Shams University

\section{Research}

Keywords: Bariatric, nausea, vomiting, aprepitant, mirtazapine, dexamethasone

Posted Date: November 18th, 2020

DOI: https://doi.org/10.21203/rs.3.rs-107678/v1

License: (c) (1) This work is licensed under a Creative Commons Attribution 4.0 International License.

Read Full License 


\section{Abstract \\ Background}

Co-administration of different antiemetics proved to decrease postoperative nausea and vomiting (PONV) following laparoscopic sleeve gastrectomy (LSG). The investigators compared the combination of aprepitant and dexamethasone (A/D) with the combination of mirtazapine and dexamethasone (M/D) for prevention of PONV in morbidly obese patients undergoing LSG.

\section{Methods}

Ninety patients scheduled for LSG were assigned to receive a single preoperative dose of dexamethasone $8 \mathrm{mg}$ IVI (D group), and in addition to oral aprepitant $80 \mathrm{mg}$ (A/D group) or oral mirtazapine $30 \mathrm{mg}$ (M/D group) in a randomized, double-blind trial. Assessment of PONV was done $0-2 \mathrm{~h}$ (early) and 2-24 hours (late). Patients' level of sedation, satisfaction and postoperative pain were also assessed.

\section{Results}

$A / D$ and $M / D$ groups were superior to $D$ group for complete response $0-24 \mathrm{~h}$ after surgery $(79.3 \%$ for $A / D$ group, $78.6 \%$ for $M / D$ group and $20.7 \%$ for $D$ group). $D$ group was inferior to $A / D$ and $M / D$ groups regarding collective PONV and use of rescue antiemetics $(P<0.001) 0-24 \mathrm{~h}$ after surgery. The peak nausea scores $2-24 \mathrm{~h}$ were significantly lower in both $A / D$ and $M / D$ groups vs. $D$ group $(P=0.005)$. Patients in the M/D group showed higher sedation scores while those in $A / D$ groups showed lower pain scores and less analgesic requirements. $A / D$ and $M / D$ groups were superior to $D$ group regarding the patient's satisfaction score.

\section{Conclusion}

$A / D$ and $M / D$ combinations were superior to $D$ alone regarding the proportion of patients exhibiting a complete response in preventing PONV associated with LSG.

\section{Trial Registration:}

Clinical Trials. gov Identifier: NCT04013386/ prospectively registered: 09/07/2019, http://www.Clinical Trial.gov

\section{Background}


Laparoscopic sleeve gastrectomy (LSG) has a tremendous growth over the last decade as a treatment of morbid obesity ${ }^{(1)}$. However, its associated postoperative nausea and vomiting (PONV) agonize nearly $48 \%$ of those patients and not only result in distressing patients but also may delay discharge from postanesthesia care unit and increase annual coast ${ }^{(2)}$. This incidence is even increased in female gender, younger age, non-smoker, history of PONV or motion sickness, increased duration of anesthesia and the use of postoperative opioids ${ }^{(3)}$. The limited efficacy of PONV following LSG with single antiemetic encouraged evaluation of several antiemetic combination strategies ${ }^{(4)}$.

Dexamethasone is a glucocorticoid with a half-life of $36-48 \mathrm{~h}^{(5)}$ being used in a dose of $8-10 \mathrm{mg}$ for preventing PONV in patients undergoing chemotherapy and surgery because of its low cost and its limited side effects ${ }^{(6)}$. It may exert its action through prostaglandin antagonism, prevention of release of serotonins in the gut and potentiation of other antiemetics by sensitizing the pharmacological receptor (7). Prophylactic use of dexamethasone in combination with $5-\mathrm{HT}_{3}$ receptor antagonist $\left(5-\mathrm{HT}_{3} \mathrm{RA}\right)$ in patients at high risk of PONV was associated with lower use of rescue antiemetics during early or late postoperative periods than dexamethasone or $5-\mathrm{HT}_{3} \mathrm{RA}$ mono-therapy ${ }^{(8)}$.

Aprepitant is a selective neurokinin-1 (NK-1) receptor antagonist with a half-life of $9-12 \mathrm{~h}$ and it is active against opioid-induced vomiting, used for chemotherapy-induced nausea and vomiting (CINV) and PONV prophylaxis ${ }^{(9,10)}$. Aprepitant markedly prevents both acute and delayed emesis in CINV and PONV for the first $24-48 \mathrm{~h}^{(9)}$. Combination of $5-\mathrm{HT}_{3} \mathrm{RA}$ and aprepitant resulted in lower incidence of PONV ${ }^{(10)}$.

Mirtazapine is a noradrenergic and specific serotonergic antidepressant (NaSSA) that selectively blocks postsynaptic $5-\mathrm{HT}_{2}$ and $5-\mathrm{HT}_{3}$ receptors. As it blocks receptors associated with nausea and vomiting, mirtazapine has been reported to be effective in controlling CINV and PONV (11). Mirtazapine is rapidly and well absorbed from the gastrointestinal tract after oral administrations and peak plasma concentrations are reached within 2 hours. The longer elimination half-life of mirtazapine (ranges from 20-40 h) justifies once-a-day dosing ${ }^{(12)}$.

The research team conducted this study to test the hypothesis of decreasing the incidence of PONV following LSG by using aprepitant/dexamethasone and mirtazapine/dexamethasone combinations versus dexamethasone alone and to highlight any associated side effects of both combinations and accordingly patients`satisfaction.

\section{Methods}

The study protocol was approved by the institute ethics committee (FMASU R 36/ 2019) and registered with the ClinicalTrials.gov (NCT04013386) before enrollment of patients and a written informed consent was obtained by every patient. This double-blind randomized controlled study was conducted at AinShams university hospitals from the 15th of July 2019 till the 31st of December 2019 on 90 patients, aged between 25-55 years old, both sexes, ASA physical status I or II and body mass index (BMI) $\geq$ 
$35 \mathrm{~kg} / \mathrm{cm}^{2}$ undergoing LSG. Patients who were with gastrointestinal disorders, with clinically significant major organ disease, received antidepressant or an anti-emetic drug within $48 \mathrm{~h}$ before surgery or on treatment with systemic glucocorticoids within 4 weeks before surgery were excluded.

Randomization of the patients was performed using a computer-generated random numbers concealed in sealed opaque envelopes and a nurse randomly chose the envelope that determined the group of assignment. Patients were allocated into three equal groups (30 each) with 1:1:1 ratio according to PONV prophylaxis ; aprepitant/ dexamethasone (A/D) group; each patient received $80 \mathrm{mg}$ aprepitant capsule and a placebo tablet (matching mirtazapine) orally with sips of water and dexamethasone $8 \mathrm{mg}$ intravenous infusion (IVI) $2 \mathrm{~h}$ preoperatively, mirtazapine/ dexamethasone (M/D) group; each patient received $30 \mathrm{mg}$ mirtazapine tablet and placebo capsules (matching aprepitant) orally with sips of water and dexamethasone $8 \mathrm{mg} \mathrm{IVI} 2 \mathrm{~h}$ preoperatively and dexamethasone (D) (control) group; each patient received a placebo capsule and a placebo tablet (matching aprepitant and mirtazapine) orally with sips of water and dexamethasone $8 \mathrm{mg}$ IVI $2 \mathrm{~h}$ preoperatively. Dexamethasone $8 \mathrm{mg}$ was administered diluted in $100 \mathrm{ml} 0.9 \%$ normal saline (NS) IVI over $15 \mathrm{~min}$.

Aprepitant was presented as Emend® capsules manufactured by: Alkermes Pharma Ireland Limited, Athlone, Ireland. Mirtazapine was presented as Remeron ${ }^{\circledR}$ tablets N.V. Organon Oss, The Netherlands and dexamethasone was presented as dexamethasone sodium phosphate ampoules $8 \mathrm{mg}$ in $2 \mathrm{ml}$, MUP, Egypt. The study drugs were prepared by the hospital pharmacy and then handed to the nurse in charge who was blinded to the nature of the medications. The placebo was an orally capsule or tablet of identical size, shape and color to aprepitant or mirtazapine but without active ingredient. Both the patients and the anesthetists who evaluated and recorded all data of PONV were unaware of treatment assignment.

Patients were prepared by 8 hours fasting before their scheduled operation and routine aspiration prophylaxis was administered with slowly IV over $10 \mathrm{~min}$. Patients were transferred to the operating room without sedative premedication and were admitted to the operating table in the ramp position. On arrival in the operating room, routine monitoring was applied and venous access was established with two widebored cannulae. A central venous catheter placement was planned in patients who had difficult venous access. preparation for difficult airway was managed with patient's pre-oxygenation with $100 \% \mathrm{O}_{2}$ for $5 \mathrm{~min}$ before induction of anesthesia and a rapid-sequence intubation was carried out with propofol (1.0$1.5 \mathrm{mg} / \mathrm{kg}$ ) (according to lean body weight) and rocuronium $(0.6 \mathrm{mg} / \mathrm{kg}$ ) (according to ideal body weight), fentanyl (1.5-2 ug/ kg) (according to ideal body weight). Anesthesia was maintained with $1.2-2 \%$ sevoflurane in 50\% air/oxygen to keep the bispectral index (BIS) value at 40-60 and intermittent doses of muscle relaxant if needed to maintain adequate muscle relaxation throughout the procedure. Mechanical ventilation was maintained by putting patients on controlled ventilation mode targeting end-tidal $\mathrm{CO}_{2}$ at 35-40 mmHg. During laparoscopy, intra-abdominal pressure was maintained at $12-14 \mathrm{mmHg}$ by carbon dioxide insufflator and the patients was placed in $20-30^{\circ}$ head up position. All surgical procedures were completed by the same surgeon. At the end of surgery, sevoflurane administration was ceased; atropine $0.02 \mathrm{mg} / \mathrm{kg}$ and neostigmine $0.05 \mathrm{mg} / \mathrm{kg}$ were given IV for antagonism of neuromuscular blockade. After 
satisfactory recovery, patients were extubated and transferred to the post-anesthesia care unit (PACU) where they were monitored with ECG, NIBP, and pulse oximetry.

Postoperatively, intravenous ketorolac Amp (30 mg) diluted in $100 \mathrm{ml}$ 0.9\% NS IVI over 15 min was administered every 8 , or as requested by the patients. Postoperative pain intensity was rated by the patients using a $10-\mathrm{cm}$ the Visual Analogue Scale (VAS) device, with $0=$ no pain and $10=$ the worst pain imaginable. Time to the first dose of postoperative analgesia was recorded. The ward nurses were instructed to omit the eight hourly doses if they considered that the patient was pain free (pain levels below four). The patient's level of sedation was assessed 1 hour preoperatively after taking the study drug (before induction of anesthesia) and at $24 \mathrm{~h}$ postoperative using Ramsay Sedation Scale ${ }^{(13)}$.

The postoperative data (e.g. vital signs, pain, and sedation scale) were collected every $4 \mathrm{~h}$. The occurrences of early $(0-2 h)$, delayed $(2-24 h)$ and total $(0-24 h)$ PONV were recorded by anesthesia residents blinded to the patient's group assignment. Nausea was defined as a subjective unpleasant sensation associated with awareness of the urge to vomiting. Vomiting was the forceful expulsion of gastric contents from the mouth.

The severity of postoperative nausea was assessed using a 4-point verbal descriptive scale (VDS) as follows $^{(14)}$ : (0-1 (no nausea), 1-4 (mild), 4-7 (moderate) and 7-10 (severe)). If patients experienced intractable nausea for at least $10 \mathrm{~min}$, or more than one emetic episode post-operatively for at least $15 \mathrm{~min}$, they received a rescue dose of metoclopramide $10 \mathrm{mg}$ IV. The primary end point was the complete response rate within $24 \mathrm{~h}$ of surgery. Complete response was defined as nausea $<4$ (VDS) and no administration of rescue antiemetic during $24 \mathrm{~h}$ after surgery. Incidence of side effects (headache, pruritis, dizziness, somnolence or dry mouth, hypotension or extra-pyramidal manifestations) and patient's satisfaction (using a 7-point Likert-verbal rating scale) ${ }^{(15)}$ were recorded.

\section{Analysis of Data:}

Depending on (Talebpour et al., 2017) ${ }^{(16)}$ who found that promethazine group significantly reduced the incidence of PONV in the first 24 hours compared with the metoclopramide group (41\% vs. $97.5 \%$ ), assuming the power $=0.80$ and $a=0.05$, and by using PASS 11th release, the minimal sample size was 18 patients in each group ${ }^{(17)}$. The research team recruited 30 patients in each group for better precision.

\section{Statistical methods:}

The collected data were coded, tabulated and statistically analyzed using IBM SPSS statistics (Statistical Package for Social Sciences) software version 22.0, IBM Corp., Chicago, USA, 2013. Descriptive statistics were done for quantitative data as mean \pm SD (standard deviation) for quantitative data, while it was done for qualitative data as number and percentage. Inferential analyses were done for quantitative variables using Shapiro-Wilk test for normality testing and ANOVA test. In qualitative data, inferential analyses for independent variables were done using Chi square test for differences between proportions and Fisher's Exact test for variables with small expected numbers. Post hoc Bonferroni test was used to 
find homogenous groups in cases of significant differences among the study groups. The level of significance was taken at $P$ value $<0.050$ is significant, otherwise is non-significant.

\section{Results}

102 patients were screened for eligibility, out of which 90 patients were included who were randomly assigned to $A / D, M / D$ and $D$ groups. 86 patients completed the study (4 patients were omitted from analysis) (Fig. 1). The study groups didn't show any significant difference in mean age, BMI, ASA status, history of smoking, history of motion sickness and/or PONV. In concordance to that, the intra-operative variables of duration of surgery and mean given intravascular fluid volume were similar between groups (Table 1).

In the early postoperative period ( $0-2$ hours), there were statistically significant differences between the $A / D$ group and the $D$ group in the number of vomiting episodes $(P=0.029)$ with no significant differences between the $A / D$ and $M / D$ groups. There were no statistically significant differences between the studied groups regarding nausea episodes, collective PONV, rescue antiemetic usage and the number of patients exhibiting a complete response (Table 2).

In the late postoperative period (2-24 hours), there were statistically significant differences between the $M / D$ group and $D$ group regarding the incidence of nausea episodes $(P=0.005)$ with no statistically significant differences between the A/D and M/D groups. The number of vomiting episodes, collective PONV, rescue antiemetic usage and the proportion of patients exhibiting a complete response were statistically significant lower in the $A / D$ and $M / D$ groups compared to $D$ group $(P=0.016, P<0.001, P<$ $0.001, P<0.001$ respectively) with no statistically significant differences between the $A / D$ and $M / D$ groups (Table 2).

For the period from 0 to 24 hours, there were statistically significant differences between the M/D group and $D$ group regarding the incidence of nausea episodes and grade of nausea $(P=0.029, P=0.012$ respectively) with no statistically significant differences between the $A / D$ and $M / D$ groups (Table 2). The number of vomiting episodes was statistically significant higher in the $D$ group compared to $A / D$ group $(P<0.001)$ with no statistically significant differences between the $A / D$ and $M / D$ groups (Table 2), (Fig. 2). The Collective PONV, the rescue antiemetic usage and the proportion of patients exhibiting a complete response were statistically significant lower in the $A / D$ and $M / D$ groups compared to $D$ group $(P<0.001, P<0.001, P<0.001$ respectively) with no statistically significant differences between the $A / D$ and $M / D$ groups. The probability of complete response relative to $D$-group was in $M / D$ group close to in A/D group (Fig. 3). Some cases had nausea in the early post-operative period and then had vomiting later, so the frequency of collective PONV at 0-24 hour was less than the gross sum of nausea episodes and vomiting episodes either alone. (Table 2)

Preoperative and postoperative sedation scores were statistically significant higher in the M/D group compared to $A / D$ and $D$ groups $(P<0.001, P<0.001$ respectively) with no statistically significant differences between the A/D and $D$ groups (Table 3 ). 
There were statistically significant differences between the A/D group and $D$ group regarding the pain score at $0-2 \mathrm{~h}(P<0.001)$ with no statistically significant differences between the $A / D$ and $M / D$ groups. The pain score at 2-24 $\mathrm{h}$, the analgesia time and rescue analgesic doses were statistically significant higher in the $D$ group compared to $A / D$ and $M / D$ groups with statistically significant differences between the $A / D$ and $M / D$ groups $(P<0.001, P<0.001, P<0.001$ respectively) (Table 3 ).

Incidences of the studied side effects weren 't statistically significantly among the three groups and no patient required treatment for adverse effects (Table 3). The satisfaction score was statistically significantly higher in the $A / D$ and $M / D$ groups compared to $D$ group with statistically significant differences between the $A / D$ and $M / D$ groups $(P<0.001)$ (Table 3 ).

\section{Discussion}

This study demonstrated favorable response rates regarding the efficacy of a single dose of dexamethasone $8 \mathrm{mg}$ IVI in combination with oral aprepitant $80 \mathrm{mg}$ or oral mirtazapine $30 \mathrm{mg}$ versus dexamethasone alone regarding the proportion of patients exhibiting a complete response in preventing PONV for morbidly obese patients undergoing LSG (Table 1).

Nearly half of patients suffered from PONV after bariatric surgery ${ }^{(2)}$. PONV not only agonize patients but also can lead also to dehydration and electrolytes imbalances and possibly increase hospital length of stay or even cause readmission. Alleviating PONV is a corner stone for achieving excellence in anesthetic management for such patients however; a standard regimen is yet to be identified ${ }^{(18)}$.

All patients in this study were considered to be high risk of PONV and required perioperative preventive treatment. Since the prophylactic efficacy of single antiemetic in high-risk patients is limited, a multimodal approach including 2 or more interventions is recommended ${ }^{(3)}$. The study design didn 't include a group without prophylactic medication since it would be unethical to deny such high-risk patients any preventive treatment for PONV. Dexamethasone $8 \mathrm{mg} \mathrm{IVI} \mathrm{was} \mathrm{used} \mathrm{as} \mathrm{an} \mathrm{active-control.}$

The dose of combined aprepitant and dexamethasone was based on a previous study conducted by Kawano et al. ${ }^{(19)}$, administering preoperative aprepitant $80 \mathrm{mg}$ capsule plus dexamethasone $8 \mathrm{mg}$ IVI had efficacious antiemetic effect in patients at high-risk of PONV from epidural fentanyl analgesia. While the preoperative dose of mirtazapine $30 \mathrm{mg}$ tablet plus dexamethasone $8 \mathrm{mg}$ was based on a study done by Chen et al ${ }^{(20)}$, found that premedication with this combination significantly reduced PONV in patients undergoing gynecological procedures. The timing and the administration of a preoperative single dose of dexamethasone IVI was based on a meta-analysis study conducted by De Oliveira et al., ${ }^{(21)}$.

Dexamethasone has been used for many years to reduce the incidence of PONV ${ }^{(5-8,21)}$. Currently, it is recommended as a single perioperative injection of 8-14 $\mathrm{mg}$ to decrease PONV in the first $24 \mathrm{~h}$ after surgery ${ }^{(22)}$. It also has analgesic effects, improves respiratory parameters, decreases fatigue, low-cost drug and promotes better recovery $(3,19,21,22)$. However, PONV prophylaxis with dexamethasone $(8 \mathrm{mg})$ IV 
increases postoperative blood glucose values in non-diabetic and diabetic patients, irrespective of baseline blood glucose levels ${ }^{(23)}$.

NK1 receptor antagonists (aprepitant) has been shown to be effective in decreasing post-operative vomiting rather than nausea, this might be due to its deferential affinity for NK1 receptors at peripheral and central levels. It is considered a useful prophylactic antiemetic in bariatric and neurosurgery operations and was found to be effective either alone or in combination to other antiemetic ${ }^{(10,24)}$. In concordant with our study, Kakuta et al., ${ }^{(25)}$ concluded that a single preoperative dose of oral aprepitant $80 \mathrm{mg}$ significantly lowered PONV 2-24 h after surgery and pain medications used by patients undergoing laparoscopic gynecological procedures. Concomitant with our results, Jeyabalan, et al, (26) concluded that a single dose of aprepitant $40 \mathrm{mg}$ was equally effective to ondansetron $8 \mathrm{mg}$ in 3 doses, $8 \mathrm{~h}$ apart, in preventing PONV, reducing the severity of nausea and number of rescues antiemetics during $24 \mathrm{~h}$ postoperative period in 125 women undergoing breast and thyroid surgeries. Partially consistent with our study, Moon et al, ${ }^{27}$ recruited 93 patients scheduled to undergo laparoscopic gynecological surgery under general anesthesia to evaluate the effect of a single oral aprepitant $40 \mathrm{mg}$ vs. palonosetron $0.075 \mathrm{mg}$ IV on PONV and found that nausea severity was significantly lesser in the aprepitant group at 0 and $2 \mathrm{~h}$ after administration and greater amounts of rescue analgesics were required in the aprepitant group. Also, Gan et al. ${ }^{(28)}$ concluded patients assigned to receive a single preoperative dose of oral aprepitant $40 \mathrm{mg}$ or oral aprepitant $125 \mathrm{mg}$, vs. ondansetron $4 \mathrm{mg}$ IV that aprepitant was superior to ondansetron while Diemunsch et al., ${ }^{(29)}$, found that aprepitant was non- inferior to ondansetron in the prevention of vomiting over $0-24 \mathrm{~h}$, however they failed to show any statistically significant difference in peak nausea scores, complete response or rescue antiemetic use, which can be explained by the fact that nausea is subjective and the threshold or the frequency for administration of rescue therapy for nausea and vomiting episodes may have differed among institutions or clinical staff caring for the patient.

Study results were supported with the findings of Sinha et al., ${ }^{(10)}$ who evaluated the prophylactic efficacy of adding oral aprepitant $(80 \mathrm{mg})$ to ondansetron $4 \mathrm{mg}$ IV on PONV in morbidly obese patients undergoing laparoscopic bariatric surgery vs. ondansetron alone and reported statistically significant reduction in incidence of vomiting episodes at $72 \mathrm{~h}$ after surgery.

In concordant with our study, Kawano et al. ${ }^{(19)}$, who reported that the combination of oral aprepitant $80 \mathrm{mg}$ and dexamethasone $8 \mathrm{mg}$ IV had a statistically significant lower incidence of vomiting episodes from continuous epidural fentanyl analgesia at $24 \mathrm{~h}$ after surgery compared to dexamethasone alone in patients scheduled for elective knee osteoarthritis surgery. Also Habib et al., ${ }^{(30)}$ found that the combination of oral aprepitant $40 \mathrm{mg}$ and dexamethasone $10 \mathrm{mg}$ IV was more effective than the combination of ondansetron and dexamethasone for prophylaxis against postoperative vomiting in adult patients undergoing craniotomy under general anesthesia. Furthermore, in contrast to our study, the study designed by Bilgen et al., ${ }^{(31)}$ reported that dexamethasone $8 \mathrm{mg} \mathrm{IV} /$ oral aprepitant $40 \mathrm{mg}$ did not improve the complete response for PONV compared to dexamethasone $8 \mathrm{mg}$ IV/ondansetron $4 \mathrm{mg}$ IV in patients undergoing laparoscopic surgery. 
Our results correlated with the study of Chang et al., ${ }^{(11)}$ who reported that a single preoperative oral mirtazapine $30 \mathrm{mg}$ decreased the incidence, delayed the onset and reduced the severity of nausea and vomiting after orthopedic surgery induced by intrathecal morphine in patients undergoing spinal anesthesia. Also, Omran et al. ${ }^{(32)}$ reported that oral mirtazapine $30 \mathrm{mg}$ premedication significantly reduced preoperative anxiety and the incidence of postoperative early nausea and late vomiting compared with ondansetron $16 \mathrm{mg}$ IV in 80 female patients undergoing breast surgery. Similarly, Teixeira et al., ${ }^{(33)}$ evaluated the use of oral mirtazapine $30 \mathrm{mg}$ once per day for 2 to 8 months in two morbidly obese patients who underwent gastric bypass and suffered nausea and vomiting 1 month after the operation and reported disappearance of nausea and vomiting within days after beginning the medication.

The combination of dexamethasone with a $5-\mathrm{HT}_{3}$ receptor antagonist was recommended for high-risk patients ${ }^{(30,31)}$. Concomitant with our results, Chen et al., ${ }^{(20)}$ evaluated the effect of premedication with oral mirtazapine $30 \mathrm{mg}$ plus dexamethasone $8 \mathrm{mg}$ versus dexamethasone $8 \mathrm{mg}$ alone in 80 moderate and high-risk female patients undergoing gynecological surgery under general anesthesia and found that the combination of mirtazapine plus dexamethasone effectively reduced the level of preoperative anxiety and the incidence of late PONV. The reduction of PONV risk in M/ D group compared to $D$ group confirmed that mirtazapine (with $5-\mathrm{HT}_{3}$ blocking properties) ${ }^{(11)}$ similarly reduced the PONV risk as has been shown with other $5-\mathrm{HT}_{3}$ receptor antagonists. Similarly, Hsu et al., ${ }^{(34)}$ reported that single oral mirtazapine $30 \mathrm{mg}$ premedication in combination to dexamethasone $8 \mathrm{mg}$ plus droperidol $1.25 \mathrm{mg}$ reduced the incidence of postoperative nausea and vomiting in moderate to high risk patients.

Our study confirmed the analgesic effects of aprepitant in A/D group and mirtazapine in M/D group compared to dexamethasone alone which were supported with other studies using aprepitant $(25,26)$ and mirtazapine ${ }^{(35-37)}$. In contrast to our study, Moon et al, ${ }^{(27)}$ documented that greater amounts of rescue analgesics were required in the aprepitant group.

Mirtazapine has also the advantage of alleviating preoperative anxiety in a variety of elective surgical procedures ${ }^{(38)}$. Those results coincided with our results that confirmed the sedative effect of mirtazapine as evidenced by lower Ramsay sedation scores in patients pre-medicated with mirtazapine.

This study has many merits; First, the investigators used an evidence based, a low-cost drug and safe antiemetic medication; dexamethasone as baseline prophylactic anti-emetic. Other study medications; aprepitant and mirtazapine have oral forms with long lasting effects up to 24 hours and cheaper than ondansetron (19). Together with dexamethasone, they developed additive effects due to their different antiemetic mechanisms of action. Second, the rescue antiemetic used; metoclopramide $10 \mathrm{mg}$ IV has acceptable side effects profile and its mechanism of action (D2 receptor blockade) ${ }^{(19)}$ is also different from both baseline and studied drugs. Third, the randomized and double-blind design decreased the possibility of bias. 
The study however had some limitations; first: the baseline risk of PONV was not evaluated due to the usage of dexamethasone as a baseline anti-emetic, however, all studied patients were considered high risk for PONV and it would be unethical to deny such high-risk patient any PONV preventive treatment, second: aprepitant is more expensive than mirtazapine, therefore, a cost-effectiveness analysis of the study drugs was necessary, third: groups were not matched for comorbidities and fourth; the study was conducted in a single center and on a relatively small sample size.

\section{Conclusions}

Aprepitant/dexamethasone and mirtazapine/dexamethasone combinations were superior to dexamethasone alone regarding the proportion of patients exhibiting a complete response in preventing PONV associated with LSG. Despite that aprepitant/dexamethasone combination had significantly better patient satisfaction than mirtazapine/dexamethasone and dexamethasone, yet its high cost may render it not to be cost effective for PONV prophylaxis. The research team also concluded that mirtazapine with its cheap, availability, favorable pharmacokinetic and pharmacodynamics profile and its analgesic, sedative and anti-emetic potentials provide a good choice as a premedication for morbidly obese patients undergoing bariatric surgeries.

\section{Abbreviations}

PONV: Post-operative nausea and vomiting; LSG:laparoscopic sleeve gastrectomy; $5 \mathrm{HT}_{3}: 5-$ hydroxytryptamine receptor type 3; 5- $\mathrm{HT}_{3} \mathrm{RA}: 5-\mathrm{HT}_{3}$ receptor antagonist; NK-1:neurokinin-1; CINV:chemotherapy-induced nausea and vomiting; NaSSA:noradrenergic and specific serotonergic antidepressant; PACU:post-anesthesia care unit; VAS:Visual Analogue Scale; VDS:verbal descriptive scale.

\section{Declarations}

\section{Ethics approval and consent to participate}

Ethical approval from Ain Shams University hospitals research committee was obtained (FMASU R 36/ 2019)). Written informed consent was taken from all the patients, their parents or their guardians before any study procedure was conducted.

\section{Consent for publication}

Not applicable.

\section{Availability of data and materials}

The data that support the findings of this study are available from Ain Shams university hospitals and they are not publicly available. Data are however available from the corresponding author on reasonable request after permission of Ain Shams university. 


\section{Competing interests}

The authors declared that they had no competing interests.

\section{Funding}

No funding was obtained for this study.

\section{Authors' contributions}

T.A and I.M.E. were responsible for the conception and design of the study, analysis of the data, writing the manuscript and revising the manuscript. D.K. and A. H were responsible for clinical cases handling, collect the data and search the database. All authors have read and approved the manuscript.

\section{Acknowledgements}

The research team would thank residents of anesthesia and the nursing staff working in main operation theater, Ain-Shams University Hospitals for their valuable help in this work.

\section{Authors' Information}

1-Tarek Mohamed Ashoor: Lecturer, MD, Department of Anesthesia and Intensive Care, Faculty of Medicine, Ain-shams, Cairo, Egypt, Corresponding author Tel: +20 01092241039, Email: tarekashoor@med.asu.edu.eg

2- Dina Y. Kassim: Assistant Professor, MD, Department of Anesthesia and Intensive Care, Faculty of Medicine, Beni-Suef University, Beni-Suef, Egypt. Email: Dina.Kassim@med.bsu.edu.eg

3- Ahmed M. Hasseb: Lecturer, MD, Department of Anesthesia and Intensive Care, Faculty of Medicine, Ain-shams University, Cairo, Egypt. Email: Ahmed_hasib@med.asu.edu.eg

4-Ibrahim Mamdouh Esmat: Assistant Professor, MD, Department of Anesthesia and Intensive Care, Faculty of Medicine, Ain-shams University, Cairo, Egypt. Email: Ibrahim_mamdouh@med.asu.edu.eg

\section{References}

1. Lazoura O, Zacharoulis D, Triantafyllidis G,Fanariotis M, Sioka E, Papamargaritis D et al. Symptoms of Gastroesophageal Reflux Following Laparoscopic Sleeve Gastrectomy Are Related to the Final Shape of the Sleeve as Depicted by Radiology. Obes Surg. 2011;21(3):295-9.

2. Groene P, Eisenlohr J, Zeuzem C, Dudok S, Karcz K, Hofmann-Kiefer K. Postoperative nausea and vomiting in bariatric surgery in comparison to non-bariatric gastric surgery. Wideochir Inne Tech Maloinwazyjne. 2019;14(1):90-95.

3. Gan TJ, Belani KG, Bergese S, Chung F, Diemunsch P, Habib AS et al. Fourth Consensus Guidelines for the Management of Postoperative Nausea and Vomiting. Anesth Analg. 2020 Aug;131(2):411-448. 
4. Apfel CC, Korttila K, Abdalla M, Kerger H, Turan A, Vedder I, et al. A factorial trial of six interventions for the prevention of postoperative nausea and vomiting. N Engl J Med. 2004 10;350(24):2441-51.

5. Gupta P, Jain Postoperative nausea and vomiting prophylaxis: A comparative study of ondansetron, granisetron and granisetron and dexamethasone combination after modified radical mastectomy. Saudi J Anaesth. 2014; 8(Suppl 1): S67-S71.

6. Elhakim M, Nafie M, Mahmoud K, Atef A. Dexamethasone $8 \mathrm{mg}$ in combination with ondansetron 4 $\mathrm{mg}$ appears to be the optimal dose for the prevention of nausea and vomiting after laparoscopic cholecystectomy. Can J Anesth. 2002;49(9):922-6.

7. Henzi I, Walder B, Tramèr MR. Dexamethasone for the prevention of postoperative nausea and vomiting: a quantitative systematic review. Anesth Analg. 2000;90(1):186-94.

8. Kovac AL. Meta-analysis of the use of rescue antiemetics following PONV prophylactic failure with 5HT3 antagonist/dexamethasone versus single-agent therapies. Ann Pharmacother. 2006;40(5):87387.

9. Okafor D, Kaye AD, Kaye RJ, Urman RD. The role of neurokinin-1 (substance P) antagonists in the prevention of postoperative nausea and vomiting. J Anesthesiol Clin Pharmacol. 2017;33(4):441445.

10. Sinha AC, Singh PM, Williams NW, Ochroch EA, Goudra BG. Aprepitant's prophylactic efficacy in decreasing postoperative nausea and vomiting in morbidly obese patients undergoing bariatric surgery. Obes Surg. 2014;24(2):225-31.

11. Chang FL, Ho ST, Sheen MJ. Efficacy of mirtazapine in preventing intrathecal morphine-induced nausea and vomiting after orthopaedic surgery*. 2010;65(12):1206-11.

12. Timmer CJ, Sitsen JM, Delbressine LP. Clinical pharmacokinetics of mirtazapine. Clin Pharmacokinet. 2000;38(6):461-74.

13. Liu LL, Gropper MA. Postoperative analgesia and sedation in the adult intensive care unit. A guide to drug selection. Drugs, 2003; 63(8):755-67.

14. Boogaerts JG, Vanacker E, Seidel L, Albert A, Bardiau FM. Assessment of postoperative nausea using a visual analogue scale. Acta Anesthesiol Scand. 2000 Apr;44(4):470-4.

15. Streiner DL, Norman GR. Health measurement scales: A practical guide to their development and use. Oxford, England, UK: Oxford iversity Press; 1995. p. 28-53.

16. Talebpour M, Ghiasnejad Omrani N, Imani F, Shariat Moharari R, Pourfakhr P, Khajavi MR. Comparison Effect of Promethazine/Dexamethasone and Metoclopramide /Dexamethasone on Postoperative Nausea and Vomiting after Laparascopic Gastric Placation: A Randomized Clinical Trial. Anesth Pain Med. 2017. 22;7(4): e57810.

17. Machin D, Campbell MG, Tan SP, Tan SH. Sample Size Tables for Clinical Studies, 3rd Edition. A John Wiley \& Sons, Ltd., Publication. 2009; 5:47-57.

18. Suh S, Helm M, Kindel TL, Goldblatt MI, Gould JC, Higgins RM. The impact of nausea on postoperative outcomes in bariatric surgery patients. Surg Endosc. 2020 Jul;34(7):3085-3091. 
19. Kawano H, Matsumoto T, Hamaguchi E, Manabe S, Nakagawa M, Yamada A et al. Antiemetic efficacy of combined aprepitant and dexamethasone in patients at high-risk of postoperative nausea and vomiting from epidural fentanyl analgesia. Minerva Anestesiol. 2015 Apr;81(4):362-8.

20. Chen CC, Lin CS, Ko YP, Hung YC, Lao HC, Hsu YW. Premedication with mirtazapine reduces preoperative anxiety and postoperative nausea and vomiting. Anesth Analg. 2008 Jan;106(1):109-13.

21. De Oliveira GS Jr., Almeida MD, Benzon HT, McCarthy RJ. Perioperative single dose systemic dexamethasone for postoperative pain: A meta-analysis of randomized controlled trials. Anesthesiology 2011;115:575-88.

22. Yamanaga S, Posselt AM, Freise CE, Kobayashi T, Tavakol M, Kang SM. A single perioperative injection of dexamethasone decreases nausea, vomiting, and pain after laparoscopic donor nephrectomy. J Transplant. 2017;2017:3518103.

23. Tien M, Gan TJ, Dhakal I, et al. The effect of anti-emetic doses of dexamethasone on postoperative blood glucose levels in non-diabetic and diabetic patients: a prospective randomized controlled study. Anesthesia. 2016;71:1037-1043.

24. Singh PM, Borle A, Rewari V, Makkar JK, Trikha A, Sinha AC et al. Aprepitant for PONV: a systematic review and meta-analysis. Postgrad Med J. 2016 Feb;92(1084):87-98.

25. Jeyabalan S, Thampi SM, Karuppusami R, Samuel K. Comparing the efficacy of aprepitant and ondansetron for the prevention of postoperative nausea and vomiting (PONV): A double blinded, randomised control trial in patients undergoing breast and thyroid surgeries. Indian J Anesth. 2019 Apr;63(4):289-294.

26. Moon HY, Baek CW, Choi GJ, Shin HY, Kang H, Jung YH et al. Palonosetron and aprepitant for the prevention of postoperative nausea and vomiting in patients indicated for laparoscopic gynaecologic surgery: a double-blind randomised trial. BMC Anesthesiol. 2014 Aug 10;14:68.

27. Kakuta N, Tsutsumi YM, Horikawa YT, Kawano H, Kinoshita M, Tanaka K et al. Neurokinin-1 receptor antagonism, aprepitant, effectively diminishes post-operative nausea and vomiting while increasing analgesic tolerance in laparoscopic gynecological procedures. J Med Invest. 2011 Aug;58(3-4):24651.

28. Gan TJ, Apfel CC, Kovac A, Philip BK, Singla N, Minkowitz H et al. A randomized, double-blind comparison of the NK1 antagonist, aprepitant, versus ondansetron for the prevention of postoperative nausea and vomiting. Anesth Analg. 2007 May;104(5):1082-9.

29. Diemunsch P, Gan TJ, Philip BK, Girao MJ, Eberhart L, Irwin MG et al. Single-dose aprepitant vs ondansetron for the prevention of postoperative nausea and vomiting: A randomized, double-blind phase III trial in patients undergoing open abdominal surgery. Br J Anesth. 2007 Aug;99(2):202-11.

30. Habib AS, Keifer JC, Borel CO, White WD, Gan TJ. A comparison of the combination of aprepitant and dexamethasone versus the combination of ondansetron and dexamethasone for the prevention of postoperative nausea and vomiting in patients undergoing craniotomy. Anesth Analg. 2011 Apr;112(4):813-8. 
31. Bilgen S, Kızılcık N, Haliloğlu M, Yıldırım G, Kaspar EÇ, Köner Ö. Effect of the DexamethasoneOndansetron Combination Versus Dexamethasone-Aprepitant Combination to Prevent Postoperative Nausea and Vomiting. Turk J Anesthesiol Reanim. 2018 Sep; 46(5): 373-380.

32. Omran HASA, Nasr DAM, Eid HEA. Effect of premedication with mirtazapine versus ondansetron on postoperative nausea and vomiting in breast surgery. Egyptian Journal of Anaesthesia, 2011; 27(3):135-139.

33. Teixeira FV, Novaretti TM, Pilon B, Pereira PG, Breda MF. Mirtazapine (Remeron) as treatment for nonmechanical vomiting after gastric bypass. Obes Surg. 2005 May;15(5):707-9.

34. Hsu Y W, Ko Y P, Lao H C, Hung Y C, Chen C C. Effects of Mirtazapine Premedication on General Anesthesia and Postoperative Nausea and Vomiting. Anesthesiology 2006; 105: A626.

35. Schreiber S, Rigai T, Katz Y, Pick CG. The antinociceptive effect of mirtazapine in mice is mediated through serotonergic, noradrenergic and opioid mechanisms. Brain Res Bull.2002;30;58(6):601-5.

36. Chou WH, Lin FS, Lin CP, Lin WY, Yie JC, Sun WZ. Mirtazapine, in orodispersible form, for patients with preoperative psychological distress: A pilot study. Acta Anesthesiologica Taiwanica. 2016 March;54(1):16-23.

37. Sheen MJ, Ho ST. Mirtazapine relieves postdural puncture headache. Anesth Analg. 2008 ;107(1):346.

38. Mansour EE. Mirtazapine premedication: Effect on preoperative anxiety and propofol dose requirements at different stages of hypnosis. Egyptian Journal of Anesthesia. 2013;29(2):143-147.

\section{Tables}

Table (1): Baseline characteristics among the studied groups. 


\begin{tabular}{|c|c|c|c|c|}
\hline Variables & $\begin{array}{l}\text { A/D-group } \\
(\mathrm{N}=29)\end{array}$ & $\begin{array}{l}M / D \text { group } \\
(N=28)\end{array}$ & $\begin{array}{l}\text { D-group } \\
(\mathrm{N}=29)\end{array}$ & P-value \\
\hline Age; years & $40.6(6.1)$ & $39.1(7.3)$ & $41.5(6.0)$ & ${ }^{\wedge} 0.391$ \\
\hline BMl; kg.m-2 & $47.0(2.1)$ & $46.8(2.7)$ & $47.2(2.3)$ & ${ }^{\wedge} 0.836$ \\
\hline Sex; M/F & $16 / 13$ & $17 / 11$ & $19 / 10$ & $\# 0.722$ \\
\hline ASA; I/II & $13 / 16$ & $11 / 17$ & $13 / 16$ & \#0.888 \\
\hline Smoking; $\mathrm{n}, \%$ & $12(41.4)$ & $16(57.1)$ & $14(48.3)$ & \#0.491 \\
\hline History of motion sickness n,\% & $4(13.8)$ & $2(7.1)$ & $5(17.2)$ & $\S 0.609$ \\
\hline History of PONV; n,\% & $3(10.3)$ & $2(7.1)$ & $4(13.8)$ & $\S 0.905$ \\
\hline Operation duration; minutes & $103.1(7.3)$ & $101.9(5.4)$ & $102.9(6.8)$ & ${ }^{\wedge} 0.761$ \\
\hline Intra-operative fluids; ml & $1081.0(114.5)$ & $1098.2(76.4)$ & $1070.7(100.5)$ & ${ }^{\wedge} 0.571$ \\
\hline
\end{tabular}

${ }^{\wedge}$ ANOVA test. \#Chi square test. §Fisher's Exact test.

Table (2): Postoperative nausea and vomiting among the studied groups in the first 24 hours. 


\begin{tabular}{|c|c|c|c|c|}
\hline Variables & $A / D$ group & M/D group & D group & P-value \\
\hline \multicolumn{5}{|l|}{$\underline{0-2 h}$} \\
\hline Number of cases & 29 & 28 & 29 & \\
\hline Number of Nausea episodes; $n, \%$ & $4(13.8)$ & $3(10.7)$ & $5(17.2)$ & $\S 0.924$ \\
\hline Grade of nausea; I, II, II & $0 / 1 / 3$ & $1 / 2 / 0$ & $0 / 2 / 3$ & $\S 0.318$ \\
\hline Number of Vomiting episodes; n, \% & $0(0)^{a}$ & $3(10.7)^{a b}$ & $6(20.7)^{b}$ & $\S 0.029 *$ \\
\hline PONV; n, \% & $4(13.8)$ & $6(21.4)$ & $11(37.9)$ & $\# 0.092$ \\
\hline Use of rescue antiemetic; $n, \%$ & $3(10.3)$ & $3(10.7)$ & $9(31)$ & $\# 0.060$ \\
\hline Complete response; n, \% & $26(89.7)$ & $25(89.3)$ & $20(69)$ & $\# 0.060$ \\
\hline \multicolumn{5}{|l|}{ 2-24h } \\
\hline Number of cases & 26 & 25 & 20 & \\
\hline Number of Nausea episodes; $n, \%$ & $6(23.1)^{a b}$ & $3(12)^{a}$ & $11(55)^{b}$ & $\# 0.005^{*}$ \\
\hline Grade of nausea; I, II, II & $1 / 3 / 2$ & $2 / 1 / 0$ & $0 / 4 / 7$ & $\S 0.061$ \\
\hline Number of Vomiting episodes; n, \% & $1(3.8)^{a}$ & $3(12)^{a b}$ & $7(35)^{b}$ & $\S 0.016 *$ \\
\hline PONV; n, \% & $7(26.9)^{a}$ & $6(24)^{a}$ & $18(90)^{b}$ & $\#<0.001 *$ \\
\hline Use of rescue antiemetic; $n, \%$ & $3(11.5)^{a}$ & $3(12)^{a}$ & $14(70)^{b}$ & $\#<0.001 *$ \\
\hline Complete response; n, \% & $23(88.8)^{a}$ & $22(88)^{a}$ & $6(30)^{b}$ & $\#<0.001 *$ \\
\hline \multicolumn{5}{|l|}{ - } \\
\hline \multicolumn{5}{|l|}{$\underline{0-24 h}$} \\
\hline Number of cases & 29 & 28 & 29 & \\
\hline Number of Nausea episodes; n, \% & $10(34.5)^{a b}$ & $6(21.4)^{a}$ & $16(55.2)^{b}$ & $\# 0.029 *$ \\
\hline Grade of nausea; I, II, II & $1 / 4 / 5^{a b}$ & $3 / 3 / 0^{a}$ & $0 / 6 / 10^{b}$ & $\S 0.012 *$ \\
\hline Number of Vomiting episodes; n, \% & $1(3.4)^{a}$ & $6(21.4)^{a b}$ & $13(44.8)^{b}$ & $\# 0.001 *$ \\
\hline PONV; n, \% & $10(34.5)^{a}$ & $11(35.7)^{a}$ & $27(93.1)^{b}$ & $\#<0.001 *$ \\
\hline Use of rescue antiemetic; $n, \%$ & $6(20.7)^{a}$ & $6(21.4)^{a}$ & $23(79.3)^{b}$ & $\#<0.001 *$ \\
\hline Complete response; n, \% & $23(79.3)$ a & $22(78.6)^{a}$ & $6(20.7)^{b}$ & \#<0.001* \\
\hline
\end{tabular}


\#Chi square test. §Fisher's Exact test. *Significant. Homogenous groups had the same symbol $(a, b, c)$ by post hoc Bonferroni test.

Table (3): Postoperative findings among the studied groups; data presented as mean and SD or number and percentage as appropriate.

\begin{tabular}{|c|c|c|c|c|}
\hline Variables & $\begin{array}{l}\text { A/D-group } \\
(\mathrm{N}=29)\end{array}$ & $\begin{array}{l}\text { M/D group } \\
(\mathrm{N}=28)\end{array}$ & $\begin{array}{l}\text { D-group } \\
(\mathrm{N}=29)\end{array}$ & P-value \\
\hline \multicolumn{5}{|l|}{ Sedation } \\
\hline RAMSAY score preoperative & $1.5(0.5)^{a}$ & $2.3(0.5)^{b}$ & $1.2(0.4)^{a}$ & ${ }^{\wedge}<0.001 *$ \\
\hline RAMSAY score postoperative & $1.7(0.8)^{a}$ & $2.9(0.6)^{b}$ & $1.3(0.5)^{a}$ & ${ }^{\wedge}<0.001 *$ \\
\hline \multicolumn{5}{|c|}{ Postoperative Pain and analgesia } \\
\hline Pain score $0-2$ hour & $2.1(0.7)^{a}$ & $2.2(0.6)^{a}$ & $2.8(0.7)^{b}$ & ${ }^{\wedge}<0.001 *$ \\
\hline Pain score 2-24 hour & $2.3(0.5)^{a}$ & $3.8(0.4)^{b}$ & $4.3(1.1)^{\mathrm{c}}$ & ${ }^{\wedge}<0.001 *$ \\
\hline Analgesia time; hours & $89.3(21)^{a}$ & $77.9(17.1)^{b}$ & $53.4(13.4)^{c}$ & ${ }^{\wedge}<0.001 *$ \\
\hline Rescue analgesic dose; mg & $40.7(17.7)^{a}$ & $59.3(15.4)^{b}$ & $70.3(15.7)^{c}$ & ${ }^{\wedge}<0.001^{*}$ \\
\hline \multicolumn{5}{|l|}{ Side effects } \\
\hline Headache; n,\% & $2(6.9)$ & $2(7.1)$ & $1(3.4)$ & $\S 0.867$ \\
\hline Dizziness; $n, \%$ & $3(10.3)$ & $1(3.6)$ & $2(6.9)$ & $\S 0.867$ \\
\hline Dry mouth ; $\mathrm{n}, \%$ & $1(3.4)$ & $2(7.1)$ & $2(6.9)$ & $\S 0.867$ \\
\hline Somnolence; $n, \%$ & $0(0)$ & $2(7.1)$ & $0(0)$ & $\S 0.103$ \\
\hline Diarrhea ; n,\% & $1(3.4)$ & $0(0)$ & $0(0)$ & $\S 1.000$ \\
\hline Any side effect $; n, \%$ & $5(17.2)$ & $6(21.4)$ & $3(10.3)$ & $\S 0.509$ \\
\hline \multicolumn{5}{|l|}{ Satisfaction } \\
\hline Satisfaction score & $5.4(1.6)^{a}$ & $3.8(1.4)^{b}$ & $2.7(1.3)^{c}$ & ${ }^{\wedge}<0.001 *$ \\
\hline
\end{tabular}


^ANOVA test. \#Chi square test. §̧Fisher's Exact test. *Significant. Homogenous groups had the same symbol $(a, b, c)$ by post hoc Bonferroni test.

\section{Figures}

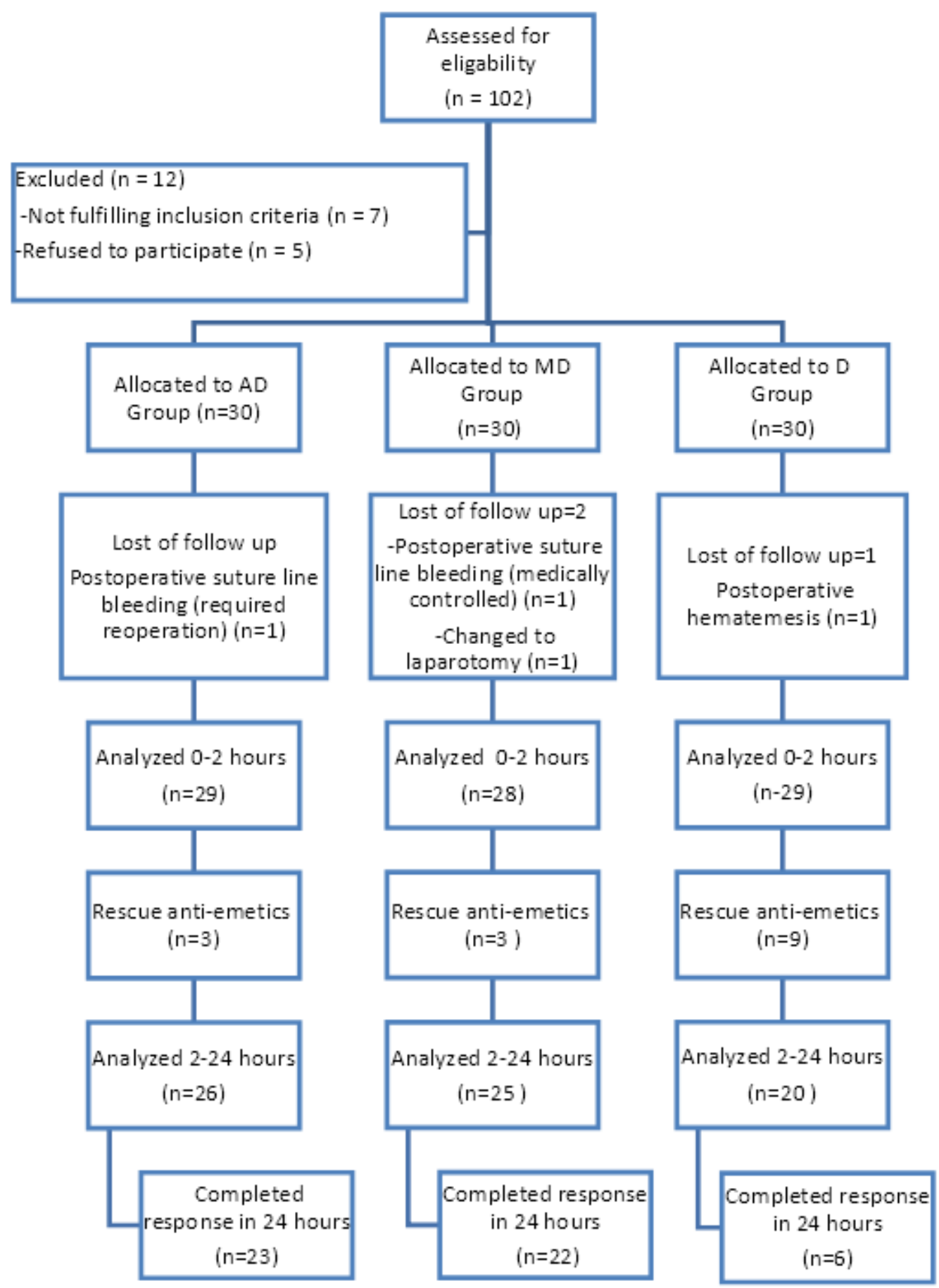

\section{Figure 1}

Flow chart of the study. 


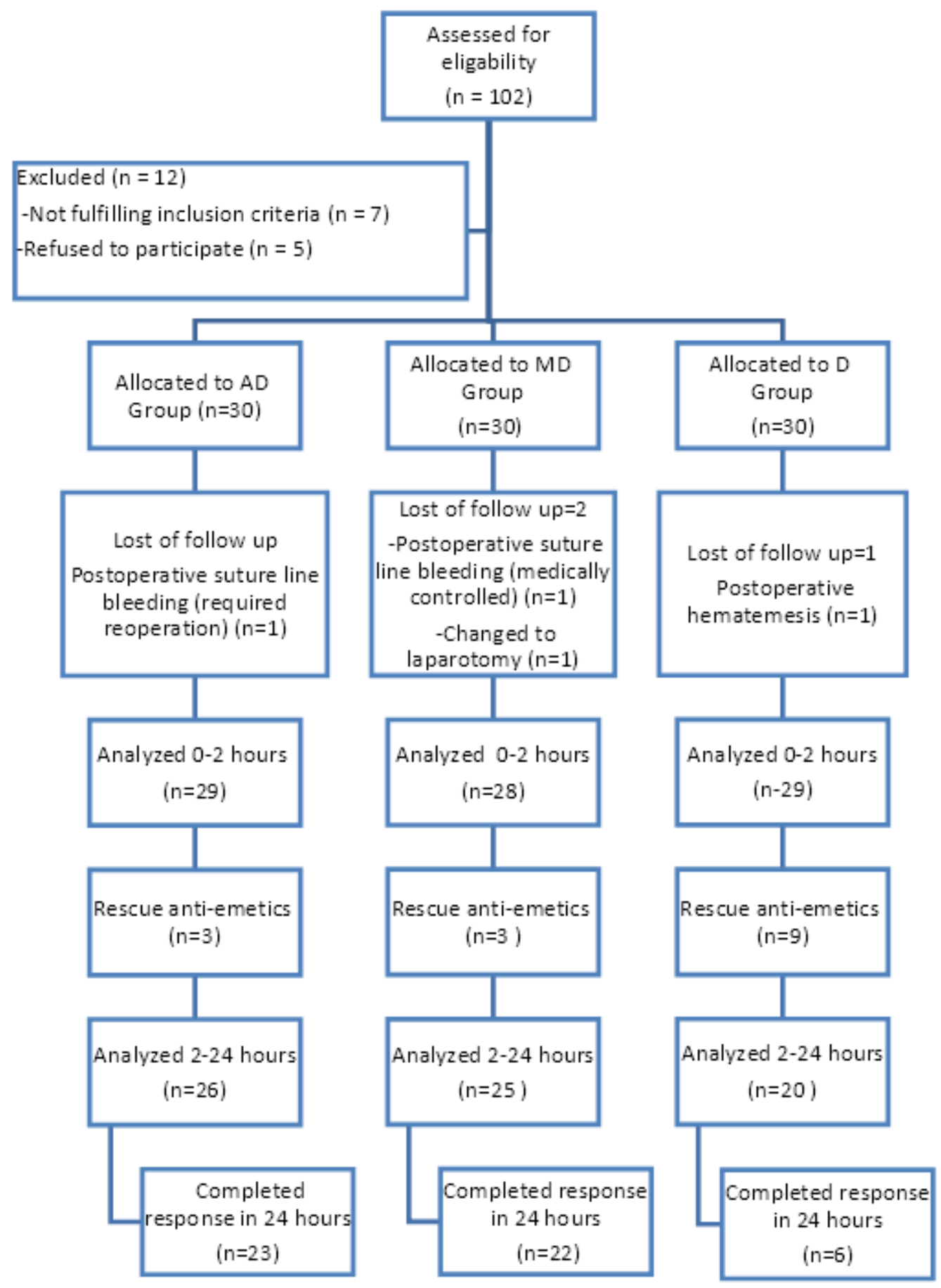

Figure 1

Flow chart of the study. 


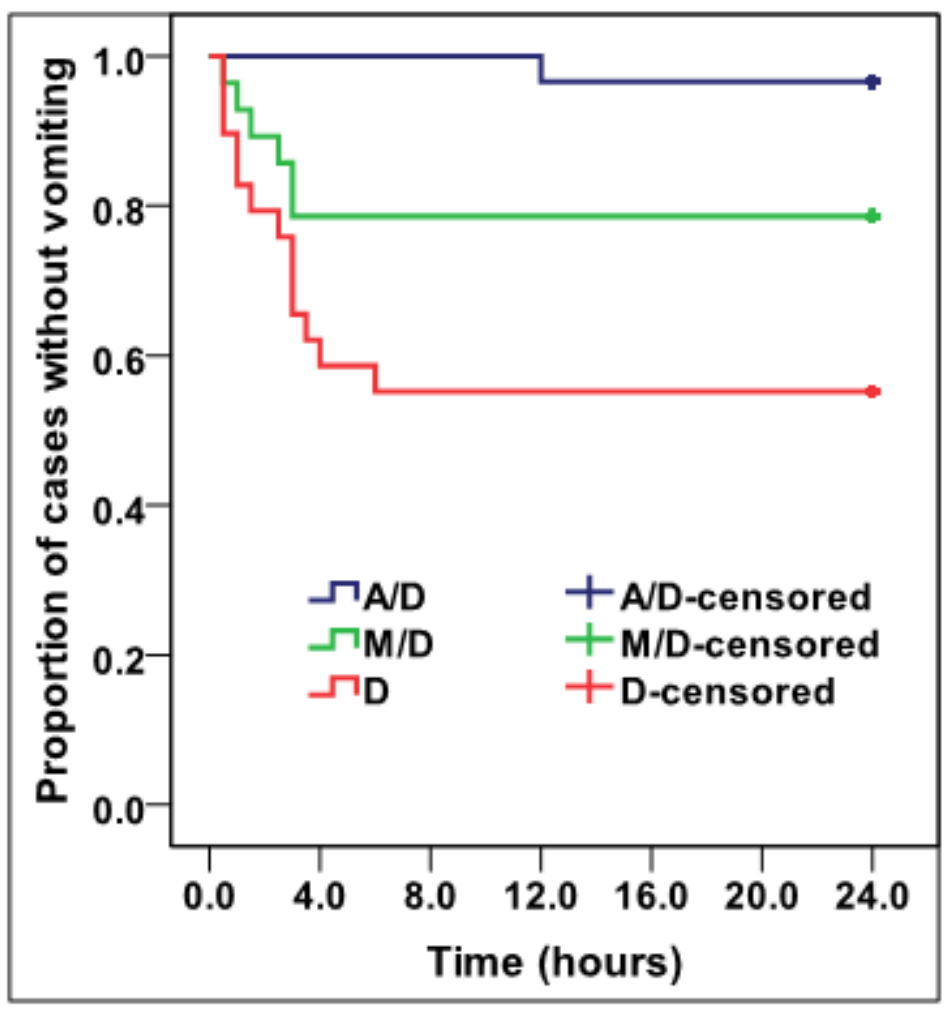

Figure 2

Kaplan Meier curve for vomiting rate (Log rank test, $\mathrm{P}<0.001)$

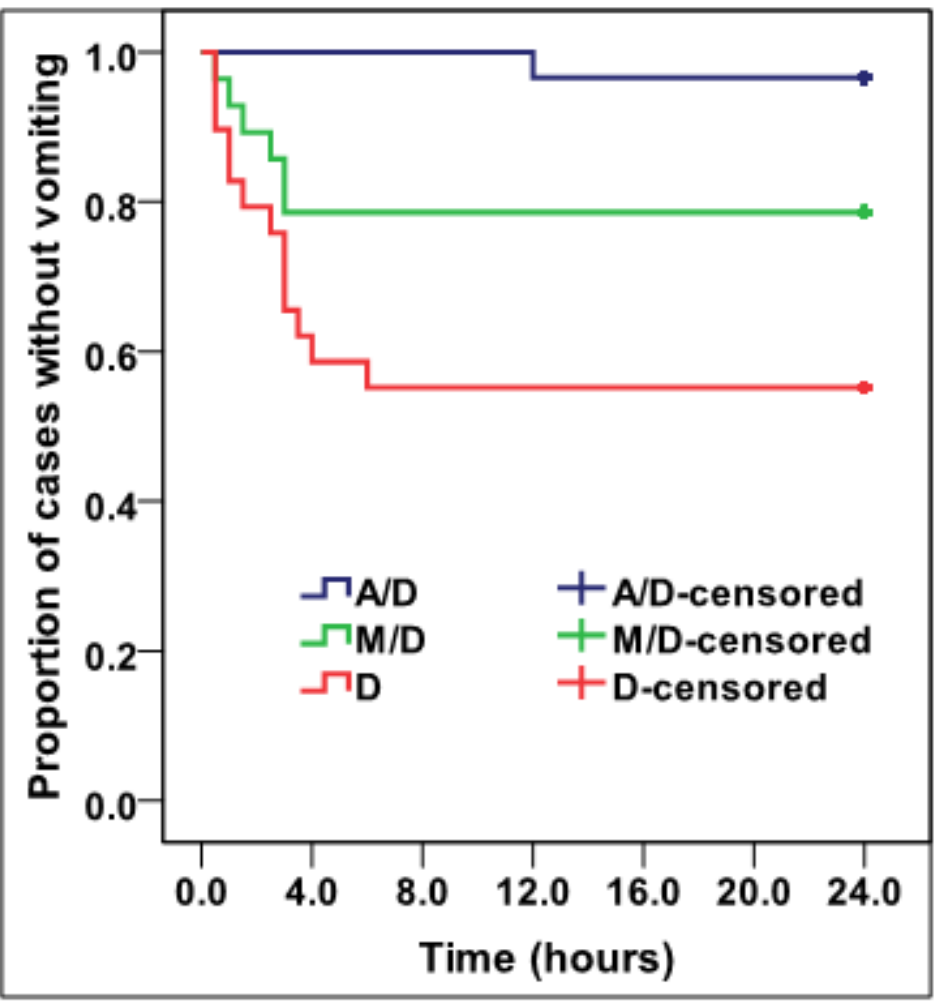

Figure 2

Kaplan Meier curve for vomiting rate (Log rank test, $\mathrm{P}<0.001$ ) 


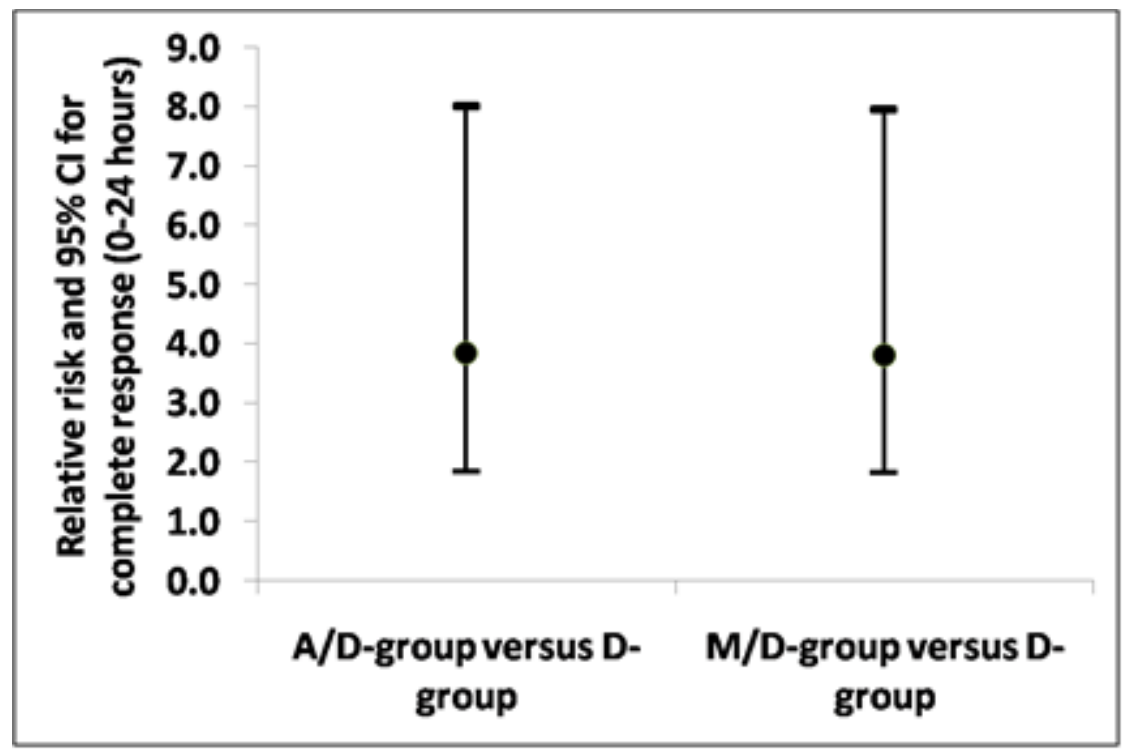

\section{Figure 3}

Relative risk with $95 \% \mathrm{Cl}$ for $\mathrm{A} / \mathrm{D}$ group vs. M/D group for complete response in the first 24 hours after surgery; showing that the probability of complete response relative to D-group was in MD group close to in AD group.

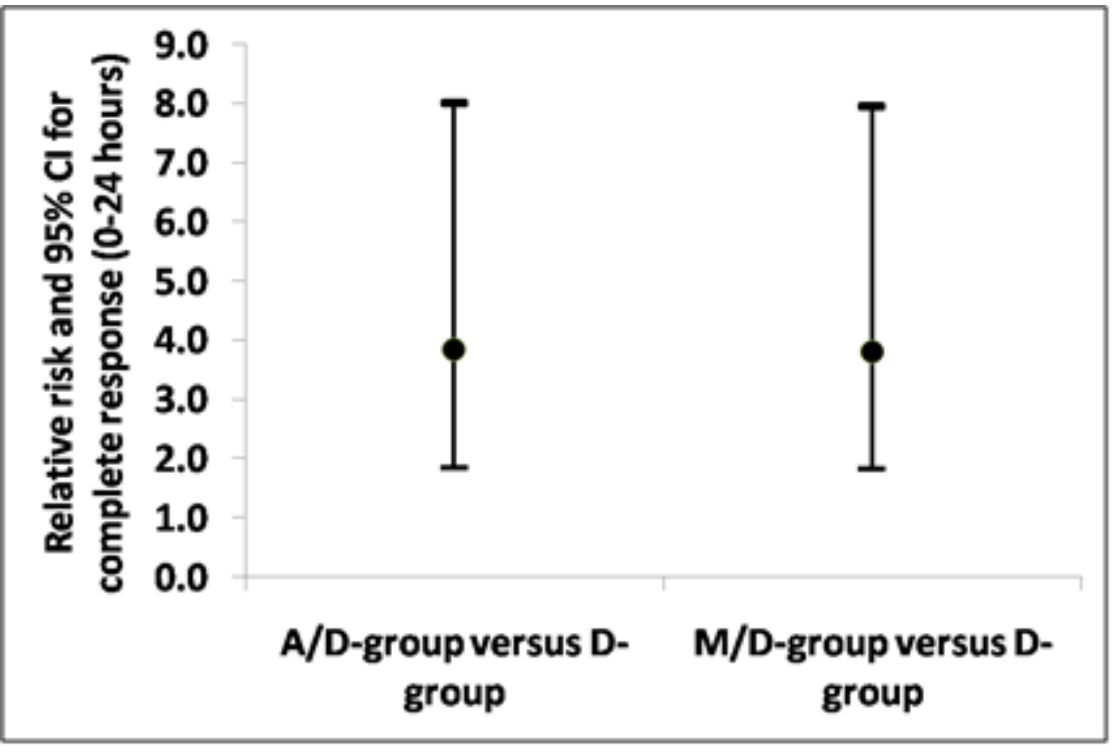

\section{Figure 3}

Relative risk with $95 \% \mathrm{Cl}$ for $\mathrm{A} / \mathrm{D}$ group vs. M/D group for complete response in the first 24 hours after surgery; showing that the probability of complete response relative to D-group was in MD group close to in $A D$ group. 